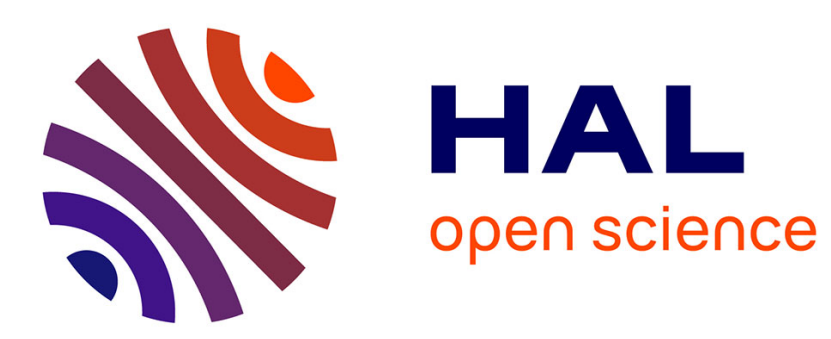

\title{
Dry etching of single crystal PMN-PT piezoelectric material.
}

\author{
Joël Agnus, Ioan Alexandru Ivan, Samuel Queste
}

\section{To cite this version:}

Joël Agnus, Ioan Alexandru Ivan, Samuel Queste. Dry etching of single crystal PMN-PT piezoelectric material.. 24th International Conference on Micro Electro Mechanical Systems, MEMS'11., Jan 2011, Cancun, Mexico. pp.237-240. hal-00566569

\section{HAL Id: hal-00566569 https://hal.science/hal-00566569}

Submitted on 16 Feb 2011

HAL is a multi-disciplinary open access archive for the deposit and dissemination of scientific research documents, whether they are published or not. The documents may come from teaching and research institutions in France or abroad, or from public or private research centers.
L'archive ouverte pluridisciplinaire HAL, est destinée au dépôt et à la diffusion de documents scientifiques de niveau recherche, publiés ou non, émanant des établissements d'enseignement et de recherche français ou étrangers, des laboratoires publics ou privés. 


\title{
DRY ETCHING OF SINGLE CRYSTAL PMN-PT PIEZOELECTRIC MATERIAL
}

\author{
Joel Agnus ${ }^{1}$, Ioan Alexandru Ivan ${ }^{1}$ and Samuel Queste ${ }^{2}$ \\ ${ }^{1}$ FEMTO-ST / UFC / ENSMM / CNRS UMR6174, Dpt. AS2M, Besançon, FRANCE \\ ${ }^{2}$ FEMTO-ST, MIMENTO Centre, Besançon, FRANCE
}

\begin{abstract}
During the last decade, the applications of PMN-PT spread significantly. Unlike PZT, the appropriate microtechnologies for PMN-PT Piezo-MEMS aren't fully documented in the literature. This paper deals with the PMN-PT etching by inductively coupled plasma (ICP) technique, also known as DRIE. The paper quantitatively presents the etching parameters of PMN-PT by the $\mathrm{Ar} / \mathrm{C}_{4} \mathrm{~F}_{8}$ gas combination and reports some related useful experience.
\end{abstract}

\section{INTRODUCTION}

The ability to fabricate well-defined structures on the surface of the substrates, with near vertical sidewalls, a high aspect ratio, and a relatively low surface roughness, is a key factor for many applications, like MEMS, NEMS and integrated optical devices. High depth, high aspect ratios, good uniformity over the wafer, vertical wall profiles and reasonable etching selectivity, i.e. the ratio of the etch rates of the substrate and the mask are the actual challenges.

Plasma-based reactive ion etching (RIE) is a very controllable dry process exploiting both chemical and physical processes to remove solid material locally [1]. The plasma is generated with a powerfull RF electromagnetic field under low pressure. Accelerating ions colide with the wafer surface and eventually react with it. The effect is a combination of chemical reaction and atomic sputtering, whose balance depends on the material and method (gas concentrations, powers, substrate temperature).

Deep reactive ion etching (DRIE) using inductively coupled plasma (ICP) RIE system has demonstrated its potential in batch fabrication of deep anisotropic microstructures in Silicon. The technology is also used for highly directional and precise micro-scale etching of materials including piezoelectric. The interest is in highly integrated piezoelectric and piezo-on-silicon microsytems (from resonators and transducers to actuators and energy harvestors) [2] where traditional methods fail (e.g. mechanical lapping and trenching, ultrasonic etching).

Dry etching of piezoelectric materials is not new issue, researches being reported in quartz [3], AlN [4], $\mathrm{LiNbO}_{3}$ and PZT ceramics [5] where etching is mainly obtained by a rather physical sputtering with insignificant chemical contribution. Other newer materials with outstanding piezoelectric properties such as PMN-PT and PZN-PT are not documented in the literature.

The paper is dedicated to the investigation of dry etching of PMN-PT material and is organized as follows. After the introductory part, the Section II presents some information about the PMN-PT material and its applications in microsystems. Then, the experimental plan and the related facilities for mask deposition and dry etching are presented. The fourth section called Experimental results is the most important, presenting the graphical and numerical results. Finally, a Conclusions section is dedicated for several remarks.

\section{PMN-PT BASED MICROSYSTEMS}

In the recent years there has been an increasing interest in growing and characterizing $\mathrm{xPb}\left(\mathrm{Mg}_{1 / 3} \mathrm{Nb}_{2 / 3}\right) \mathrm{O} 3-(1-$ x) $\mathrm{PbTiO}_{3}$ (PMN-PT) [6] and $\mathrm{xPb}\left(\mathrm{Zn}_{1 / 3} \mathrm{Nb}_{2 / 3}\right) \mathrm{O}_{3}-(1-$ x) $\mathrm{PbTiO}_{3}$ (PZN-PT) [7]. Initially used as ceramics, they were grown into single crystals by modified Bridgman or solid-state single crystal growth methods and have become commercially available. Those materials exhibit outstanding piezoelectric properties (e.g. $\mathrm{d}_{33}=3500 \mathrm{pC} / \mathrm{N}, \mathrm{d}_{13}=-1200$ $\mathrm{pC} / \mathrm{N}, \mathrm{k}_{33}=0.95$ etc.) that considerably surpass the PZT ceramics by a factor of 4 to 5 [6].

During the last decade, the applications of PMN-PT increased dramatically, including high frequency bulk and surface resonators and filters, sensors and actuators, ultrasonic transducers, energy harvesters. Most applications that are not presented here apply to the classical mechanical machining (saw dicing, lapping etc.) of bulk material while others document recent MEMS micro-devices.

For instance, one of the early-patented micromachined devices is a PMN-PT composite ultrasound transducer (PCMUT). The fabrication technology is shown in [8] but with undisclosed quantitative parameters regarding DRIE method. In [9] arrays of etched cantilevers were reported to serve as acoustic sensors; equally lacking parametric details. Finally, in the recent topic review article [2] that reveals the state of the art in piezoelectric MEMS, the dry etching characteristics of most piezoelectric materials are summarized, except for the ones of PMN-PT.

The present paper is related to the authors mainstream activities in piezoelectric micro-actuators and tweezers for micromanipulation/microassembly. More recently, integrated PMN-PT piezo-actuators raised our interest, given that simulations predict improved performance [10]. Unlike PZT, the appropriate micro-technologies for PMNPT based Piezo-MEMS aren't fully documented in the literature; this paper attempts to fill a gap by quantitatively reporting the etching parameters of PMN-PT.

\section{ETCHING EXPERIMENTS \\ Material samples}

The material used for these experiments was TRS-X2C from TRS Technologies of 68\% PMM and 32\% PT 
concentration, whose cut and poling was performed in $<001>$ direction for an optimised out-of-plane operation. This type of plate possesses a longitudinal piezoelectric coefficient $d_{33}$ between 2300 and $3300 \mathrm{pC} / \mathrm{N}$. The $k_{33}$ coupling factors range from 0.90 to 0.97 . The transverse coefficients are isotropic for this type of cut, varying from -700 to $-1200 \mathrm{pC} / \mathrm{N}$ according to several intrinsic or external parameters such as material concentration, crystallographic defects and operating temperature.

A number of $\sim 30$ samples of roughly $5 \times 10 \times 0.2 \mathrm{~mm}^{3}$ were initially prepared, of which 18 were successfully tested under different conditions. The DRIE mask was of a regular type: Nickel on a thin Chrome buffer. Nickel is known as performing well under intensive etching energies. Other materials such as $\mathrm{Cr}, \mathrm{Al}$ or $\mathrm{Cu}$ were studied for etching masks but were dismissed due to low selectivity, etching chamber contamination or limited deposition thickness.
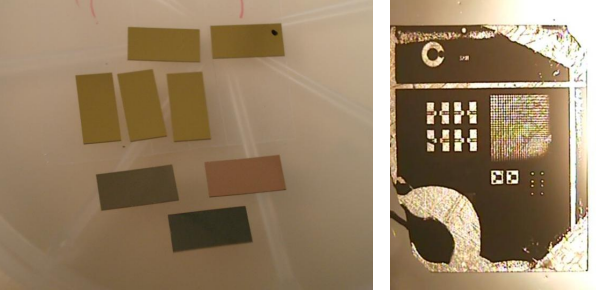

Figure 1. a) PMN-PT $5 \times 10 \mathrm{~mm}$ initial samples, b) $\mathrm{Ni}$ electroformed mask sample.

Finally, Ni sample masks were realised using three different technologies: sputtering, evaporation and electroplating. The mask features (Fig. 1.b) were developed using lift-off for the sputtering-deposited samples, wet etching for evaporated ones and electroforming for the latter
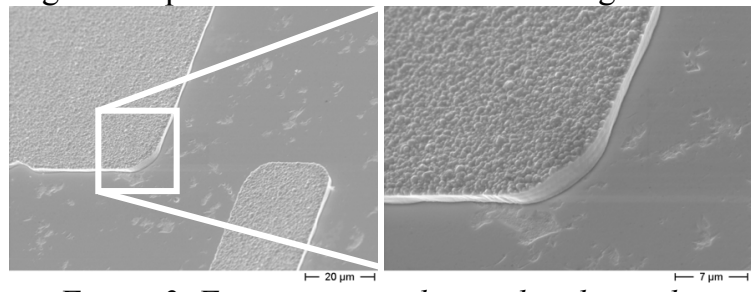

Figure 2. Feature on an electroplated sample.

\section{Mask deposition and dry etching facilities}

The sputter deposition machine was a Plassys MP500 model while the evaporation one an Alliance concept Eva 450. Provided that the nickel is known for inducing residual stress during deposition, its thickness must be limited. For the sputtering technique the maximum layer should be under $0.7 \mu \mathbf{m}$. The maximum limit for evaporated Ni on PMN-PT is larger, of around $\mathbf{1 . 5} \mu \mathrm{m}$. Finally, electrodeposited layers can be much greater, like $\mathbf{1 5} \boldsymbol{\mu m}$. Under special conditions we reached an electroplated $25 \mu \mathrm{m}$ layer, but the sample became too constrained. On the other hand, as will be seen, etching time for such a layer would take too many hours for a realistic process. A related graphical representation is provided in the figure 4 .

The ionic etching was carried out using a commercial multiplex AOE MPO 562 reactor from STS with an ICP RF generator of $3 \mathrm{~kW}$ and a RIE generator of $1.5 \mathrm{~kW}$. The maximum size of the wafer is 6 inches, and the gas available are SF6, CF4, C4F8, He, O2 and Ar.

The temperature of the substrate holder was varied between -20 and $60^{\circ} \mathrm{C}$. The gas mixture we selected was a combination $\mathrm{Ar} / \mathrm{C}_{4} \mathrm{~F}_{8} \quad(64 \mathrm{sccm} / 5 \mathrm{sccm})$. The PMN-PT samples were fixed on Si carriers with thermal grease for an optimal cooling of the sample. Step heights in $\mu \mathrm{m}$ were obtained progressively with a Tencor Alpha-step profilometer. Final profiles were also measured with a scanning electron microscope (SEM) and with a MSA-500 MEMS analyzer from Polytec. This specific tool based on Michelson interferometry may offer nanometer-scale resolution in out-of-plane direction.

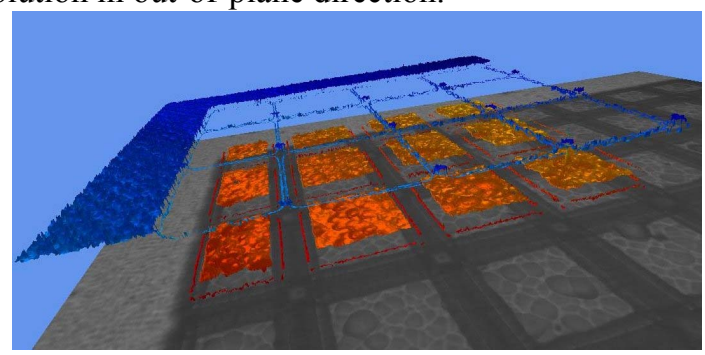

Figure 3. 3D topography picture (measurement software TMS 3.1 installed on MSA-500 analyzer)

\section{Experimental design}

Several combinations of etching parameters were chosen in the attempt of assessing as much data as possible from the 18 samples. Input parameters were:

- RF source power $(500,1200 \mathrm{~W})$,

- bias power $(100,300,400,500 \mathrm{~W})$,

- temperature $\left(-20,0,60{ }^{\circ} \mathrm{C}\right)$ and

- internal pressure (2, 5, 10, 15 mTorr).

Etching times varied from 30 minutes to 280 minutes.

\section{EXPERIMENTAL RESULTS \\ Mask Type dependence}

One of the predominant challenges in PMN-PT DRIE is the mask sufficiency, which is limited by the etching selectivity between PMN-PT and the mask and by the thickness of the mask. Ni masks can be used as mask materials because of their reasonably high growth rate, typically $17 \mu \mathrm{m} / \mathrm{h}$ for electroplated Ni. However, as the thickness of the mask is increased to several micrometers, some practical challenges or disadvantages are encountered. Nickel does not react with fluorine compounds to form volatile products. In addition to the micro-masking caused by re-deposition of the non-volatiles on the area to be etched due to mechanical erosion, electroplated metals are often non-uniform in thickness. Also, thicker hard masks may introduce severe stress on the PMN-PT wafer leading to possible breakage of the mask and the PMN-PT substrate during processing. The etch mask selectivity was studied for electroplated, evaporated $\mathrm{Ni}$ and sputtered masks at $500 \mathrm{~W}$ powers. It was shown that sputtered $\mathrm{Ni}$ gives better selectivity (12:1 compared to $8,3: 1$ for electroplated $\mathrm{Ni}$ ). But the limiting factor of $\mathrm{Ni}$ sputtered mask was the difficulty to deposit layers thicker than $1.5 \mu \mathrm{m}$ using the lift-off. 


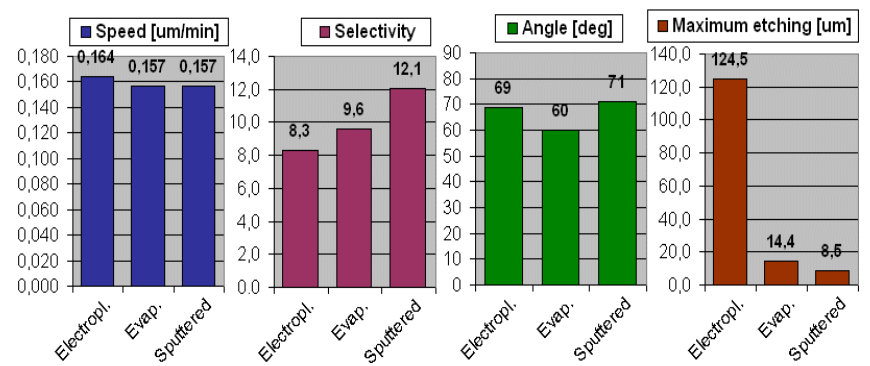

Figure 4. Comparative PMN-PT etching results for electroplated, evaporated and sputtered Ni masks. ICP parameters: $500 / 500 \mathrm{~W}, 10 \mathrm{mTorr}, 0^{\circ} \mathrm{C}, \mathrm{Ar} / \mathrm{C}_{4} \mathrm{~F}_{8}(64 / 5)$.

\section{Bias power dependence}

The etch rate decreased with the drop of bias power, from $0,14 \mu \mathrm{m} / \mathrm{min}$ for $500 \mathrm{~W}$ to $0.06 \mu \mathrm{m} / \mathrm{min}$ for $100 \mathrm{~W}$ and conversely the selectivity raised from $7,85: 1$ to $9: 1$ (Fig. 5, $\mathrm{Ni}$ evaporated mask).
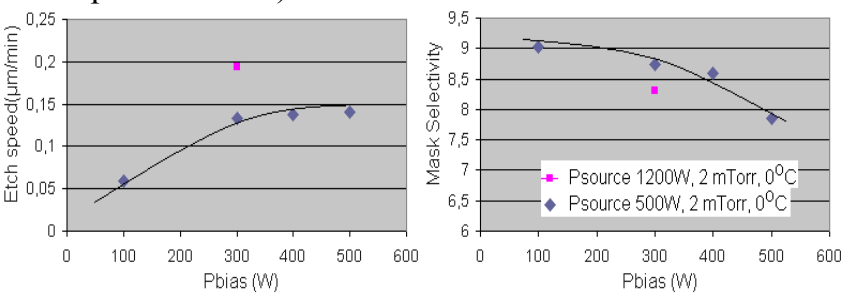

Figure 5. Etching speed and selectivity vs. bias power.
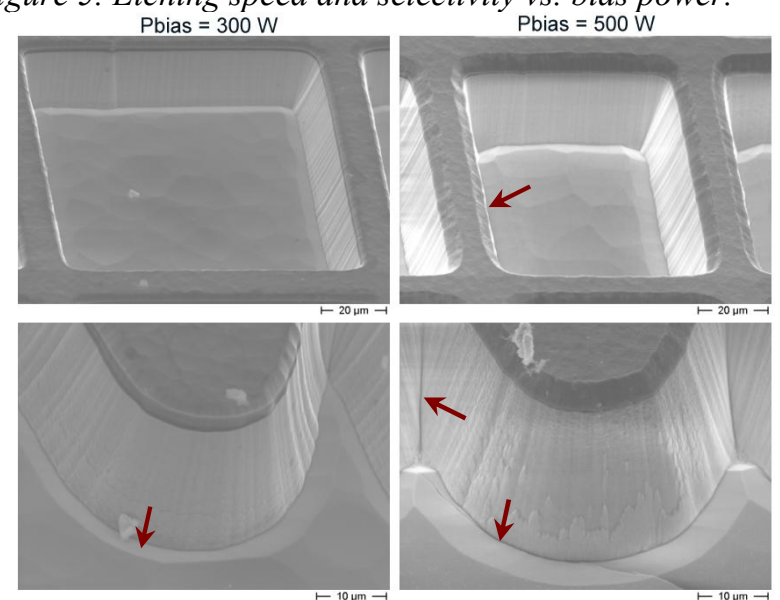

Figure 6. Effects of increased bias power (right): larger microtrenches, larger lateral mask erosion, presence of nanometer slits (arrows)

\section{Microtrenches and nanometer slits}

For the electroplated $\mathrm{Ni}$, some micro-trenches at the bottom edge of the sidewall appeared and was attributed to a higher electron density at the edges during etching, leading to higher etching speed (Fig. 6,7,9). This phenomenon was already observed for Quartz by Abe et al. [11] and was attributed to a bias voltage too high. Dahm et al. have also reported this effect [12] and interpreted this to a high flow of precursor gas. The main contribution for the appearance of this phenomenon is the bias voltage value.

Nanometer slits were also observed at the interface between very close structures. The phenomenon was also

reported in the case of PZT [13] and is not fully understood, being attributed to material ferroelectric properties.

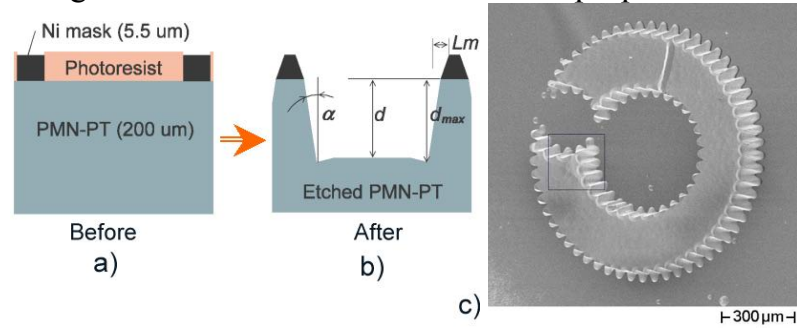

Figure 7. a,b) Electroformed test structures before and after DRIE tests. Numerical quantities for evaluating the etching rate, selectivity, sidewall angles, mask erosion and microtrenching c) SEM image of an etched feature inclined at $30^{\circ}$.

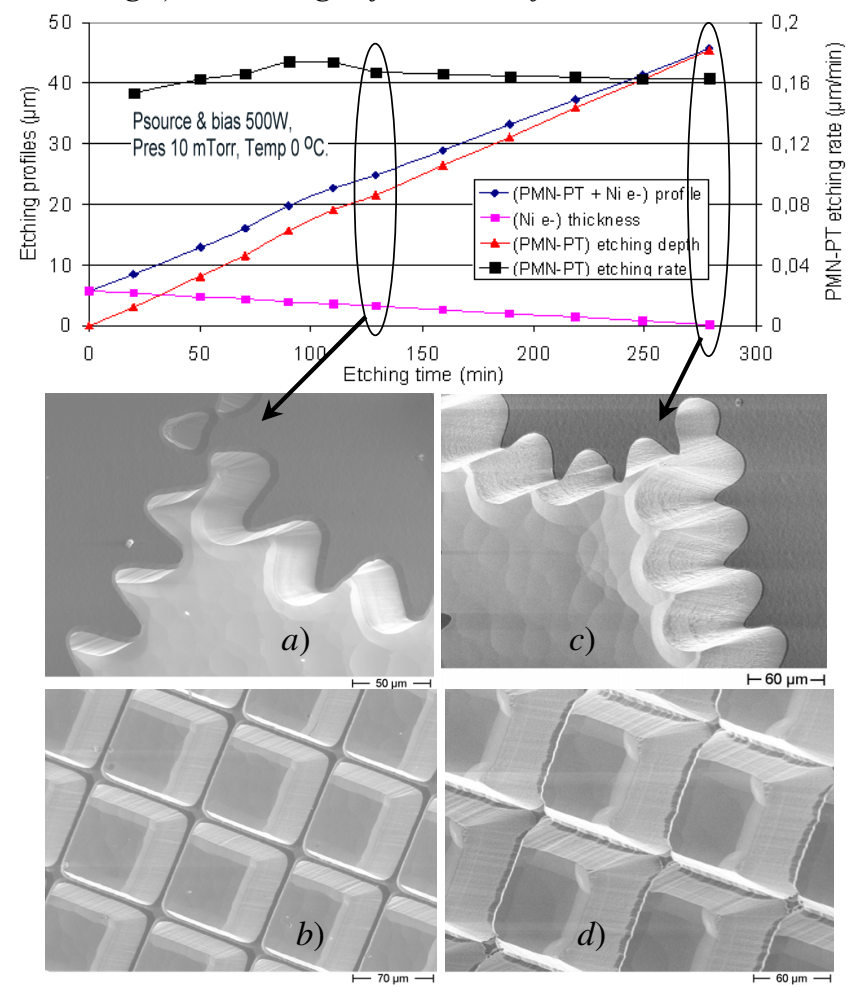

Figure 8 (up). Etchching profiles and speed diagram.

Figures 9 a,b). Zoomed SEM images taken at 130': lateral Ni mask erosion is in progress, profile is 26 um deep.

Figures 9 c,d). Same features etched after 280': profile is 47 um deep, notice the complete erosion of Ni mask (fig 9.d, except for the intersections) Sidewalls rugosity and microtrenches are increased. Ni lateral erosion. Ni redeposition.

\section{Pressure dependence}

After several tries, we have found that the lowest achievable pressure ( 2 mTorr) of the DRIE STS machine give improved results in terms of etching speed (by 10\%). The associated selectivity is however noticed to decrease quite significantly (from 10:1

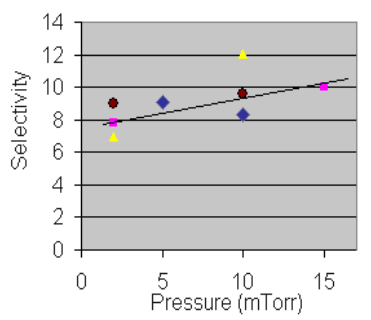

Figure 10. Selectivity vs. pressure (different param.) to 8:1) at lower pressure values (Fig.10). 


\section{Temperature Dependence}

As noticed from Fig.11 there seems no linear correlation between the etching speed and the process temperature, but the selectivity increase by several percents with the increase of the substrate holder temperature. This must be the result of a small release of the stress in the mask layer. However, due to the low Curie temperature of PMNPT material we don't recommend high temperatures etching
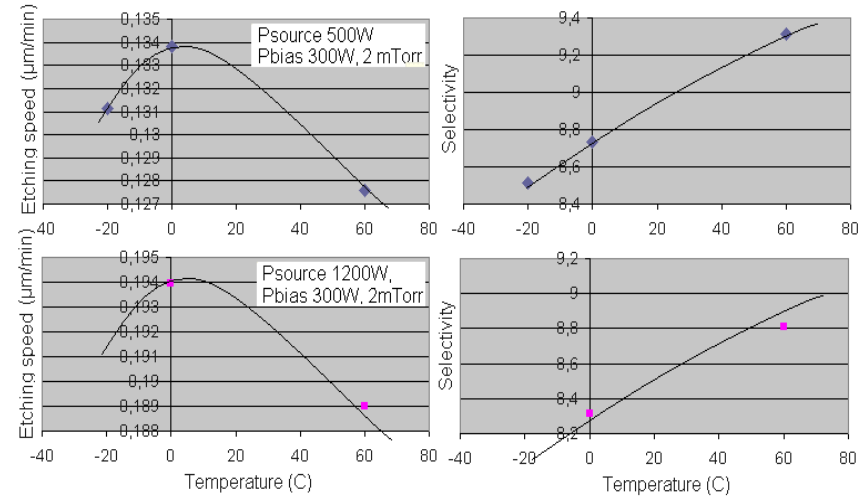

Figure 11. Etching speed and selectivity vs. temperature.

\section{Lateral mask etching}

The etching anisotropy in terms of sidewalls angles is affected mainly by lateral mask shrinking (see Fig. 6 and 9) with lateral speeds slightly superior to the vertical ones. Because of the difficulty to asses reliable results for shallow etched surfaces, data for only electroplated mask profiles were reliable. As noticed from the figures lateral erosion increase with the bias power $(18 \mathrm{~nm} / \mathrm{min}$ at $300 \mathrm{~W}$ and 22 $\mathrm{nm} / \mathrm{min}$ at $500 \mathrm{~W})$.

\section{CONCLUSIONS}

As most piezoelectric materials, the reactive component of PMN-PT etching represents an insignificant part of the process, which mainly relies on the physical sputtering of the surface atoms due to energetic ions collisions. Therefore, we used an Ar composition, knowing that the inert gases sputter yield is higher than that of other elements or molecules $\left(\mathrm{Cl}_{2}, \mathrm{C}_{2} \mathrm{H}_{6}\right.$ etc.). An experience plan was set-up in the attempt to test various parametric conditions. The

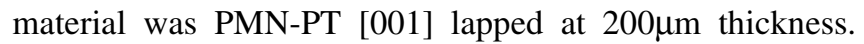
The Nickel shadowing masks were electroformed at $\sim 5.5 \mu \mathrm{m}$ or sputtered and evaporated at $0.3-0.7 \mu \mathrm{m}$ thickness.

Preliminary experience indicated the gas combination $\operatorname{Ar}(92 \%)+\mathrm{C}_{4} \mathrm{~F}_{8}(8 \%)$. We used an STS ICP machine, a couple dozens charts were obtained by varying different parameters (gas pressure, RF source and bias powers and the substrate temperature).

Best achieved etching rate was $0.19 \mu \mathrm{m} / \mathrm{min}$ with a selectivity ratio of $8: 1$ for $1200 \mathrm{~W}$ source and $300 \mathrm{~W}$ bias powers at 2 mTorr pressure. Sidewalls angles lie at $\sim 70^{\circ}$, mainly due to erosion of the $\mathrm{Ni}$ mask in lateral (horizontal) direction (Fig. 6, 9.b, 9.d). Lateral mask shrinking increased with the raise of the bias power. Expected micro-trenches at the bottom edge of the sidewall were noticed and quantified, being attributed to high local ion density at the edges during etching. Nanometer slits were also observed at the edges between structures. Compared to PZTs [5][13], (selectivity ratios of up to $35: 1$, etching speeds of $0.14 \div 0.4 \mu \mathrm{m} / \mathrm{min}$, and profile angles of $\sim 75^{\circ}$ ), we conclude that PMN-PT is slightly more renitent to dry etching than PZT. However, according to our experience, profiles of $\sim \mathbf{1 0 0} \mu \mathbf{m}$ are achievable, with the cost of extended etching times.

\section{REFERENCES}

[1] S.M. Rossnagel, J.J Cuomo, W.D. Westwood, "Handbook of Plasma Processing Technology Fundamentals, Etching, Deposition, and Surface Interactions", William Andrew Publishing/Noyes, 1990

[2] S. Tadigadapa and K. Mateti, "Piezoelectric MEMS sensors:state-of-the-art and perspectives", Meas. Sci. Technol. 20092001 (30pp), 2009

[3] S. Schreiter and H.U. Poll, "A new plasma-etching technique for micromechanical structuring of quartz", Sensors Actuators A vol. 35 pp. 137-141, 1992

[4] F.A. Khan et al "High rate etching of AlN using $\mathrm{BCl3} / \mathrm{Cl} 2 / \mathrm{Ar}$ inductively coupled plasma", Mater. Sci. Eng $B 95$ pp. 51-54, 2002

[5] A. M. Efremov et al Etching characteristics and mechanism of $\mathrm{Pb}(\mathrm{Zr}, \mathrm{Ti}) \mathrm{O} 3$ thin films in $\mathrm{CF} 4 / \mathrm{Ar}$ inductively coupled plasma", Vacuum vol. 75 pp. $321-$ 329, 2004

[6] F. Wang et al., "Complete set of elastic, dielectric and piezoelectric constants of orthorhombic $0.71 \mathrm{~Pb}(\mathrm{Mg} 1 / 3 \mathrm{Nb} 2 / 3) \mathrm{O} 3-0.29 \mathrm{PbTiO} 3$ single crystal", Appl. Phys. Lett. 90, 212903, 2007

[7] R. Zhang, B. Jiang, W. Cao, "Complete set of material constants of $0.93 \mathrm{~Pb}(\mathrm{Zn} 1 / 3 \mathrm{Nb} 2 / 3) \mathrm{O} 3-0.07 \mathrm{PbTiO} 3$ domain engineered single crystal", J. of Mat. Sci. Lett. 21, pp. 1877-1879, 2002.

[8] X. Jiang, J.R. Yuan, A. Cheng, K.Snook, P.J. Cao, et al., "Microfabrication of Piezoelectric Composite Ultrasound Transducers (PC-MUT)", Proc. 2006 IEEE Ultras. Symp., pp. 918-921, 2006.

[9] S. Hur, S. Q. Lee and H. S. Choi, "Fabrication and characterization of PMN-PT single crystal cantilever array for cochlear-like acoustic sensor", J. Mech. Sci. Tech. 24, No.1, 181-184, 2009

[10] I. A. Ivan et al., "Comparative material study between PZT ceramic and newer crystalline PMN-PT and PZNPT materials for composite bimorph actuators" Rev. Adv. Mat. Sci. Vol.24, No2, pp.1-9, 2010.

[11]T. Abe and M. Esashi, "One-chip multichannel quartz crystal microbalance (QCM) fabricated by Deep RIE", Sensors and Actuators 82, pp. 139-143, 2000.

[12] G. Dahm, I.W. Rangelow, P. Hudek and H.W.P. Koops, "Quartz etching for phase shifting masks", Microelectronic Engineering 27, pp 263-266, 1995.

[13] S. Wang et al., "Deep Reactive Ion Etching of Lead Zirconate Titanate Using Sulfur Hexafluoride Gas" $J$. Am. Ceram. Soc., 82 pp. 1339-1341, 1999 